\title{
A Silver Transformation: Chinese Monetary Integration in Times of Political
}

\section{Disintegration during 1898-1933 ${ }^{1}$}

\author{
By DEBIN MA and LIUYAN ZHAO 2
}

\begin{abstract}
This paper provides the first systematic econometric study on the evolution of Chinese silver exchange and monetary regimes during 1898-1933. Using high quality data sets of monthly and daily prices of silver dollars, we apply the threshold autoregressive models to estimate the silver points between Shanghai and other eighteen cities in Northern and Central China. We find a noticeable improvement in monetary integration between Shanghai and Tianjin from the 1910s, which then spread to other cities in our sample throughout the 1920s and 1930s. We supplement our analysis with new data sets on volumes and costs of silver flows and with an in-depth historical narrative. Our paper revaluates the efficiency of the silver regime and China's economic performance in the Republican era.
\end{abstract}

Whether the 1842 Sino-British Opium War and the forced opening of Qing China to Western imperialism and global trade marked the beginning of a century of Chinese humiliation or era of awakening to modernity may be a matter of perspectives. But the era of $1898-1933$, covered in this study, saw China's best and worst of times, straddling several sub-periods of a tumultous era in modern Chinese history. It started with China's disastrous military defeat by Japan in 1894-95 and then by Western (and Japanese) allied forces over the suppression of the Boxer Rebellion in 1901. In the wake of this defeat, Qing embarked on a bold modernization reform in 1905, modelled after Japan's Meiji Restoration, but only to collapse in 1911. China's

\footnotetext{
1 We want to thank Olivier Accominoti, Loren Brandt, Zhiwu Chen, David Chilose, Akinobu Kuroda, Dan Li, Dong Lou, James Kung, David Mitch, Hiroaki Morota, Tetsuji Okazaki, Kaixiang Peng, Thomas Rawski, Tomoko Shiroyama, Masayuki Tanimoto for comments and suggestions. We benefited from comments at seminars and workshops at Shanghai University of Finance and Economics, Hong Kong University, LSE Economic History Department, University of Maryland at Baltimore, University of Toronto, University of Tokyo, Fifth Asian Historical Economics Conference, Seoul, Korea, Fifth Annual Quantitative History Workshop, Henan, China. We are grateful for the comments of the three anonymous referees and editor of the Economic History Review, Patrick Wallis. All remaining errors are ours.

2 Author Affiliations: Debin Ma, London School of Economics and Hitotsubashi University; Liuyan Zhao, Peking University.
} 
subsequent Republican era (1911-49) begins with the Beiyang decades of 1911-27-also known as the Warlord Era-ruled by the so-called Northern regime in Beijing. It is followed by the Nanjing Decade led by the Nationalist Government based in the capital of Nanjing, only to be disrupted by a full scale Japanese invasion in 1937 .

In spite of the political turmoil, this era also saw fundamental economic and industrial transformations. ${ }^{3}$ But the monetary and financial aspect of this transformation is still relatively little understood. Throughout this period, China remained the large silver outlier at a time when most of the world were aspiring to join the gold club for prestige and respectability. ${ }^{4}$ The Chinese adherence to a silver standard in a 20th century world had long been bemoaned as a symptom of her political and economic woes and a throwback to a bygone world once drained in Spanish American silver. Furthermore the Chinese silver regime defies easy classification in that its silver basis was not in coinage, but in the form of the horseshoe shaped ingots called sycee denoted by a unit of account called tael. Sycee were minted privately, varying in shape, weight or fineness from city to city. Sycee circulated alongside other media of exchanges such as Spanish, Mexican and later other Chinese silver dollars at the same time copper cash-the only small denomination currency coined by the Imperial government—remained the dominant media for small transactions. It is important to note that as copper cash was not just a subsidiary currency, its exchange rates with silver also fluctuated across time and localities depending upon market conditions. While copper cash were mostly used for local retail transactions,

\footnotetext{
3 Brandt, Ma, and Rawski, 'From divergence to convergence'.

4 For example, Bordo and Rockoff, 'The gold standard'; Meissner, 'A new world order'; Mitchener, Shizume, and Weidenmier, 'Why did countries adopt the gold standard'.
} 
China's long-distance and wholesale trade mainly relied on silver, which is the focus of our current study.

Apart from a couple of recent studies that either focus on the world silver standard in general or China's external silver exchange (Fernholz, Mitchener, and Weidenmier, 2017; Jacks, Yan, and Zhao, 2017), we know relatively little about the operation of silver exchange and monetary regime within China. This is in sharp contrast to the large literature on the operation of the gold standard during the nineteenth and early twentieth centuries, especially on the degree of efficiency through currency exchange arbitrage. Our paper presents an in-depth analysis of China's unique silver regime and offers the first systematic econometric assessment of the Chinese silver market integration during $1898-1933.5$ We compile a large data set culled from newspapers, professional journal publications and governmental reports on exchange rates between silver dollar and tael across eighteen-nineteen cities in Northern and Central China. Our core data sets consist of monthly exchange rate data between Shanghai and Tianjin in 189833 and daily rates of nineteen cities during the 1920s and 1930s. Drawing from the mechanism of gold point arbitrage, we formalize the theory of silver point arbitrage in the presence of transaction costs across spatial markets within China and offer a threshold time series methodology for measuring silver integration comparable to that on gold points. ${ }^{6}$ We test our findings against data on actual quantities of silver flows and shipping costs during the 1920s.

Our econometric results reveal that monetary integration between Shanghai and Tianjin

\footnotetext{
5 Much of the historical studies on Chinese market integration were based exclusively on agricultural commodities. See, for example, Shiue, 'Transport costs'; Stanfield and Keller, 'Markets in China'.

${ }^{6}$ Canjels, Prakash-Canjels, and Taylor, 'Measuring market integration'.
} 
improved from the 1910s — precisely during the Warlord Era of national disintegration and civil strife - and these improvements spread to other cities in Central and Northern China in the 1920s and 30s. We offer a historical analysis on the causes behind monetary integration at a time of political disintegration, attributing a central role to China's financial and infrastructure improvements during this period. In this regard, our study on China's modern evolution reveals new insights on the limits of China's traditional monetary and financial development, an issue neglected in the ongoing Great Divergence debate. ${ }^{7}$

The rest of the article is organized as follows. We introduce the monetary system in China in the early twentieth century in Section I. Sections II presents our econometric results of the currency market integration using the monthly frequency data for Shanghai and Tianjin in 1898-1933 and daily data for eighteen cities for the 1920s and 1930s. Section III provides robustness checks on our silver points based on the quantity and cost data of silver flows. Section IV provides a historical narrative behind the money market integration. The last section concludes.

\section{I}

As the basis of the Chinese monetary system until the 1935 fiat currency reform, silver served as the denomination currency for China's international and interregional trade and as the unit of account and reserves for paper notes and interbank accounts for traditional and modern Chinese banks. Sycee, the most important traditional silver currency, were the principal medium

\footnotetext{
7 Brandt et al., 'From divergence to convergence'.
} 
for wholesale transactions and tax payment such as customs duties (Fetter and Bratter, 1936). ${ }^{8}$

They were not produced by a central authority, but minted by private smelting firm called Lufang with its imprint stamped on every shoe of sycee it produced. The sphere of circulation of any particular kind of sycee was usually confined to a local trading area. As they varied in fineness, shape, and weight, sycee had to be constantly assessed in exchange, often melted down and re-cast to conform to local standards whenever they circulated outside their local area.

The second physical form of silver currency in China was standardized silver coins (dollars), first introduced to China from Spanish America during the early 16th century. The socalled Carolus dollars had become the most popular coins in China followed by the Mexican dollars (or the eagle dollars) after the collapse of the Spanish empire in South America and founding of the new independent Republic of Mexico. In the course of centuries other dollars made their appearance, but none have enjoyed the prestige and popularity of eagle dollar in China. It was estimated that the total amount of the eagle dollar circulating in China in 1911 was 500 million, accounting for more than half of the total silver dollars circulating in China at that time. ${ }^{9}$

In 1889, the southeast province of Guangdong struck China's first silver coin, the dragon dollar. In the next ten years, other provinces also established mints which began to proliferate. All dragon dollars were modeled after the eagle dollar but the lack of uniformity hampered its appeal and diffusion. The number of dragon dollars was estimated to be only 100 million as of

${ }^{8}$ Fetter and Bratter, 'China and the flow of silver'.

9 Kann, The currencies of China, p. 145. As an example, salt revenue (the second largest government revenue after custom revenues), railway fares, and postage telegram fees were officially prescribed in eagle dollar. People's Bank of China, Shanghai Qianzhuang, p. 570. 
February 1918 , less than 10 percent of the total silver dollar stocks in China at that time. ${ }^{10}$ The founding of the new Republic brought the introduction of the national dollar (also known as the Yuan Shih-kai dollar) in 1914. To facilitate the introduction, the Beijing government arranged for the Bank of China, the Bank of Communications and the official provincial banks to exchange, free of charge, the old dragon dollars to the new national dollars. The uniformity and reliability of the national dollar made it into an unparalleled success, quickly driving out various dragon dollars, eventually eagle and other foreign dollars. According to a survey in 1924, out of the 960 million silver dollars in circulation, 750 million were the national dollars. ${ }^{11}$

Until its official abolition in the 1933 currency reform, sycee had been in concurrent circulation with silver dollars in most of the commercial places. The need for a common unit of account within the mixtures of silver currencies led to existence of various imaginary or bookkeeping tael units for different trading zones in China. Though bearing no equivalence to any actual currencies circulated, these taels served as common units of account for the amalgam of currencies in circulation. Likewise, the silver contents of these abstract tael units also varied from city to city depending upon local custom. Among them, the Shanghai tael was the most well-known, being quoted in foreign exchange market and recognized by the Shanghai Foreign Exchange Bankers Association. After the Shanghai tael, other widely used local taels were the Tianjin tael, the Hankow tael, etc., whose weight ranges approximately from 500 to 550 grains. In Table 1, we summarize the silver contents of several most important units of taels and silvers

10 People's Bank of China, Shanghai Qianzhuang, p. 164.

11 Kuroda, 'The collapse', p. 114. A number of other dollars with different designs, but with weight and fineness equal to those of the Yuan Shih-kai dollar, had been issued under the Republic. The only ones quantities were the Sun Yat-sen dollars. See Fetter and Bratter, 'China and the flow of silver'. 
dollars.

\section{Insert Table 1}

During the study period, China's silver currencies moved across space through a system of bills of exchange but increasingly by cable order. With extensive branches or agents in other cities, Shanghai native banks joint with modern banks played the leading role nationwide in silver exchanges. With the varying taels units of account in China, a transfer of silver dollar often involves conversion of multiple exchange rates as noted by Kann, 'When Shanghai is requested to remit dollars to Tianjin, both these places are required to forget that a uniform dollar is supposed to be currency in China. The transaction will invariably be coupled with the tael currency in both places. Shanghai will have to ascertain the dollar-tael rate in Tianjin and Shanghai, and Shanghai's rate for Shanghai taels against Tianjin taels. ${ }^{12}$ That is, for a Shanghai merchant to remit dollars to Tianjin, he needs first to exchange silver dollars into Shanghai taels (at Shanghai yangli) which will then be converted to Tainjin tael (subject to current exchange rate of the Shanghai tael to the Tianjin tael) in order to finally to obtain silver dollars (at Tainjin yangli) from banks in Tianjin.

The most important indicator of China's silver currency market is the dollar-tael rate, called in Chinese (and hereafter referred to as) yangli (洋厘), that is, the actual market price of silver dollars expressed by their respective abstract tael units. We now illustrate the long term trend in yangli using the case of Shanghai and Tianjin, the two most important financial centers in Central and Northern China. ${ }^{13}$ Yangli could deviate from its parity rate (the ratio of the fixed

12 Kann, The currencies of China, p. 173.

13 During the 1920s and 30s, Shanghai had been China's largest commercial and financial center, 
silver content between dollar and tael) to reflect the changing market demand for dollars in China. At the meetings held daily in the morning and early afternoon, representatives of the native banks monitored and set yangli rates in accordance with actual demand and supply conditions. In Tianjin, there had always been only one unified exchange market for dragon, eagle and national dollars throughout. ${ }^{14}$ In contrast, before August 1915, there existed in Shanghai two separate dollar exchange markets for the eagle dollar and dragon dollar (against Shanghai tael) respectively. After August 1915, the dragon dollar market was replaced by national dollar market in Shanghai. Further, by May 1919, the eagle dollar market was closed down, leaving the national dollar as the sole currency quoted in Shanghai dollar-tael market. ${ }^{15}$ Whichever types, the silver contents of dragon and national dollars approximated that of eagle dollars as revealed in Table $1 .^{16}$

We have collected the monthly observations of Shanghai yangli, Tianjin yangli, which were the average of trading days in the respective month for the period from January 1898 to March 1933, with a total of 423 observations. ${ }^{17}$ We denote Tianjin and Shanghai yangli at time $t$ with their respective tales as $y_{T, t}$ and $y_{S, t}$. Figure 1 (upper panel) plots these two series, in

absorbing about half of her foreign trade, FDI and modern manufacturing. Tianjin, located in Northern China, ranked as China's second most important commercial, financial and industrial city and the center for trade in agricultural commodities, with population increased from 200 thousand in 1840 to 1.5 million in the 1930s. See Ma, 'Economic growth'; Ma, 'Traditional finance'.

14 Jin, Guonei Shangye, p. 233.

15 People's Bank of China, Shanghai Qianzhuang, p. 573.

16 The principal dragon dollar circulated in Tianjin was the Beiyang dollar, which accurately resembled the eagle dollar. In addition, the difference of the silver contents between dragon dollars minted in major provincial mints, such as the Beiyang, Guangdong, Hubei, and Jiangnan Mints, were limited to within 1\%. Zhang, Zhonghua Bizhishi, pp. 49-56.

17 Data is taken from Kong, Nankai Jingji Zhishu, pp. 475-96. The sample period begins with Jan. 1898 because the data in Tianjin began its successive records only from that month. It ends in Mar 1933 as the dollar/tael exchange markets were closed off by the abolishment of the sycee and tael system and thus a single silver dollar standard was officially established in China. The yangli data in Shanghai are those for the eagle dollar before Aug. 1915 and for the national dollar afterward. 
the form of deviation (in percent) of silver dollars from their parity. In general, Figure 1 shows positive deviation from parity in both cities, indicating silver dollar was valued higher than its metallic contents, a premium associated with the convenience of a 'countable' coin. ${ }^{18}$ Overall, the yangli rates fluctuated widely over time and were sensitive indicators of comprehensive political and economic factors as well as consumer confidence in the money market in China. Prominent political events such as the Boxer Rebellion fiasco around 1900 and the fall of Qing Empire in late 1911 led to sharp surge in yangli. There are also notable drops as well such as 1932 reflecting the draining of silver from China's crisis stricken rural sector to cities due to the stagnation in agricultural commodity export during the Great Depression. Interestingly, it is one of the few occasions where yangli dipped substantially below parity. Besides the common global, national or regional forces impacting the yangli rates, there is a seasonal component in the yangli series related to agricultural harvests as vast majorities of dollars were transferred to facilitate agricultural trade in China. It has long been observed that May corresponded to the peak season of cocoon and tea purchase in China's central and southern regions whereas October and November would correspond to the harvest season of cotton in Northern China and rice in Central China. ${ }^{19}$ We will pick up on the seasonality issue later in the paper.

\section{Insert Figure 1}

To compare the price of silver dollars in the two cities, we collected the market exchange rates of Shanghai tael to Tianjin tael taels, called neihui in Chinese, which would also fluctuate

\footnotetext{
18 The average of deviation from parity for yangli in Shanghai and Tianjin are $1.49 \%$ and $1.96 \%$ respectively, higher than the minting cost of national dollar, which is $0.926 \%$. See National Dollar Regulations, 'State council bulletin', 631 (1914).

19 Yang, Zhongguo Jinronglun, pp. 208-13.
} 
daily and deviate from their parity values of 1.0551 as shown in Table 1. We multiply the Tianjin yangli series with the market exchange rate of Tianjin/Shanghai tales (denoted as $E_{T S, t}$ ) to place both yangli series on the common unit of Shanghai tales. If the strong form of the law of one price holds, then the prices of silver dollar measured in Shanghai taels should be the same in both markets, that is, the yangli spread (in percent) at time $t$ defined as $x_{t}=100$. $\ln \left(y_{T, t} E_{T S, t} / y_{S, t}\right)$ equals to zero. Given frictions in the form of information and trade costs, one might naturally expect deviations from the law of one price. The lower panel of Figure 1 displays the monthly series for $x_{t}$. Here, a positive (negative) value of $x_{t}$ suggests that the dollar is relatively overvalued (undervalued) in Tianjin market. Clearly, $x_{t}$ does not exhibit random walk or explosive behavior, but rather stable apart from relatively large fluctuations during the first decade of our sample period. ${ }^{20}$

Figure 2 plots the standard deviation of $x_{t}$ in a moving window of 60 observations, which reveals a sharp decline in the 1910s. Using January 1912 as the breakpoint, Qing and the Republic sub-periods accounts for about 40 percent and 60 percent of the full observations, respectively. While the mean of $x_{t}$ during the entire period is -0.10 percent with a standard deviation of 1.23 percent, the average in the first sub-period is -0.34 percent (with a standard deviation of 1.65 percent) but shrinks dramatically to only 0.07 percent in the second sub-period (with a standard deviation of 0.80 percent). To confirm this structural break without imposing a prior knowledge of the locations of breaks, we adopt endogenous breakpoint tests developed

\footnotetext{
20 The augmented Dickey-Fuller test statistic also comes is at a highly significant -7.87 . Thus, we assume stationarity in all that follows.
} 
by Bai and Perron (1998) on the 60-month moving window standard deviation series of $x_{t}$.

The sequential test results confirm one endogenous break of October 1913, which is very close to the date of political regime change. ${ }^{21}$

\section{Insert Figure 2}

For purpose of comparison, Figure 2 also plots the standard deviation of the Shanghai taelUS dollar exchange rate (deviation from mint parity), which is a good measure of Shanghai's linkage with the global market. ${ }^{22}$ It shows that while World War I wreaked havoc on ShanghaiNew York foreign exchange market, the same period marked a rapid and sustained decline in the standard deviations in the domestic exchange market in China. In other words, it seems that improvement in Chinese money market integration and efficiency gained momentum precisely at a time when the rest of the world was engulfed in turmoil.

\section{II}

As the process of silver arbitrage in spatial markets incurs costs, the shipment of silver is thought to only occur if the inherent price of silver dollar in one port is above (or below) that in the other port by a sufficient margin. In other words, one price would not prevail simultaneously in every market at all times as differences within the bounds of silver movement cost would remain. As Kann noted, 'The cost of making remittances through banks in China

\footnotetext{
21 We also calculate the standard deviation of $x_{t}$ in 36-month or 48-month moving window. The results are quite close to that from 60-month moving window. Specifically, the corresponding break date is Apr 1913 for the series in a 36-month moving window, and Feb. 1913 for the series in a 48-month moving window.

22 As a silver-standard country, China was obliged to derive the parity value of its nominal exchange rate from the price of silver in New York commodity markets. Unlike the parity of two gold currencies, the parity exchange rate is not constant in the case of the Chinese silver standard.
} 
from one place to another ought not to exceed the cost of actually shipping the coins. Otherwise, the debtor port will ship coins instead of making remittances. ${ }^{23}$

The mechanic of silver arbitrage discussed above find its close econometric representation in the threshold autoregression model. Our estimating equation is the following error correction mechanism (TECM) for yangli spread, $x_{t}$ :

$$
\Delta x_{t}=\left\{\begin{array}{cc}
k_{1}-\lambda_{1}\left(x_{t-1}-\theta\right)+v_{t}, & x_{t-1}>\theta \\
v_{t}, & \left|x_{t-1}\right| \leq \theta \\
k_{2}-\lambda_{2}\left(x_{t-1}+\theta\right)+v_{t}, & x_{t-1}<-\theta
\end{array}\right.
$$

where $\Delta x_{t}$ is the first difference of $x_{t}, k_{1}$ is a constant, and $v_{t}$ is an exogenous disturbance term and is assumed to be serially uncorrelated. Equation 1 incorporates a simple formulation of the relevant silver points, $\theta$-We refer to these estimated thresholds as 'silver points' in direct parallel to the literature on gold points. ${ }^{24}$ If the current yangli spread is above $\theta$, exploitable arbitrage opportunities emerge and silver's flow into Tianjin will occur, leading to a reversion of the yangli spread at a speed of convergence defined by $\lambda_{1}$. The case of silver outflows from Tianjin is analogous to that above. When the spread is less than $-\theta$ silver will be shipped from Tianjin and the spread will revert toward $-\theta$. Finally, when $\left|x_{t-1}\right| \leq \theta$, the spread is not large enough to overcome the costs of arbitrage, so there are no shipments for arbitrage purpose. To sum up, if the contemporaneous spread is in outer regimes, then it will revert toward the edge of the band. In the middle regime, the yangli spread will not demonstrate any tendency towards convergence, with the process of $x_{t}$ following a random walk within the 'neutral band'.

23 Kann, The currencies of China, p. 172.

${ }^{24}$ For example, Canjels et al., 'Measuring market integration'. 
Equation 1 is a special case of a 3-regime TAR model:

$$
x_{t}= \begin{cases}\beta_{0}^{u}+\sum_{i=1}^{n} \beta_{i}^{u} x_{t-i}+\varepsilon_{t}, & x_{t-1}>\theta \\ \beta_{0}^{m}+\sum_{i=1}^{n} \beta_{i}^{m} x_{t-i}+\varepsilon_{t}, & \left|x_{t-1}\right| \leq \theta \\ \beta_{0}^{l}+\sum_{i=1}^{n} \beta_{i}^{l} x_{t-i}+\varepsilon_{t}, & x_{t-1}<-\theta\end{cases}
$$

where $\varepsilon_{t}$ is an exogenous disturbance term. In this model $\operatorname{AR}(n)$ dynamics obtain in each regime. ${ }^{25}$ The process switches between three AR linear mechanisms dependent on the position of the lagged value of the process. Here, $x_{t}$ is no longer restricted to follow a random walk process in the middle regime. ${ }^{26}$ All our threshold models will be estimated using conditional least squares (CLS) estimators. The CLS approach estimates the parameters by minimizing the predictive sum of squared errors. The optimization need only be done with $\theta$ searched over some interval that guarantees any regimes have adequate data for estimation. ${ }^{27}$

\section{II.1. Monthly data for Shanghai and Tianjin, 1898-1933}

We first estimate the restricted model as in equation 1 on our Shanghai-Tianjin yangli spread, using the full sample period from $1898-1933 .^{28}$ We restrict the grid search to values such that the upper and lower regimes combined have at least 10 percent, and at most 70 percent of the observations. The results are presented in Table 2. The threshold is estimated to be 1.44 percent for the entire sample. To acknowledge the dramatic changes in the yangli spread series

\footnotetext{
25 If we restrict $n=1, \beta_{1}^{u}=\beta_{1}^{l}, \beta_{i}^{m}=1$, and some appropriate constrains on constants, eq. 2 is reduced to eq. 1 .

26 Once the effect of speculation is considered, $x_{t}$ in the middle regime within the silver point band can still be characterized as a stationary process. See the analogous mechanism on the gold standard in Officer, 'The remarkable efficiency'.

27 This approach has the advantage that the threshold parameter can be searched without any constraints. Under mild conditions, including stationarity and that the true conditional mean function is a discontinuous function, the CLS method is consistent. Cryer and Chan, Time series, p. 403.

28 All commonly used methods for testing linear versus nonlinear models that appear in the literatureincluding the Tsay test and the likelihood ratio test (Chan, 'Percentage points') — strongly reject linearity for $x_{t}$, suggesting that a threshold model is more appropriate than a linear AR model.
} 
in the 1910s, we also estimate equation 1 using January 1912 as the break date for two subperiods. The results indeed show dramatic changes in the thresholds in two sub-periods. The silver point is estimated to be 2.48 percent in the Qing Empire era before 1912 but reduces substantially to 0.88 percent in the Republican era, shrinking by almost two-thirds. ${ }^{29}$ The changes in threshold strongly point to increasing market integration from the 1910s. It should be noted that, for each period, the residual series are clearly not uncorrelated over time, as reflected by the highly significant Ljung-Box Q statistics. Meanwhile, the Chan statistics suggest that remaining nonlinearities are somewhat problematic for equation 1 as applied for the full period. ${ }^{30}$ We suppose that the problems might be caused by strict constraints, such as a single lag in AR processes in the outer regimes or the unit root in middle regime.

\section{Insert Table 2}

We now proceed to estimate using general TAR model as in equation 2. This allows for higher-order AR processes and nonrandom walk behavior in inner band. To discriminate between models with different values of $n$, we choose $n=3$ or 2 as these serve to minimize the values of the Schwarz Information Criterion. Table 3 shows the results from the entire period and sub-periods. For each period, there is no material change in the silver point estimates using either the restricted model or the general model. In particular, both models confirm a significant decline in the silver points after the 1910s. Compared to the earlier results, the Chan statistics

\footnotetext{
29 All threshold models are stationary given the estimated coefficients in Tab. 2. Note that the region of stationarity for a TAR model is substantially larger than the region defined by the linear AR model inspired constraints $\left|1-\lambda_{1}\right|<1$ and $\left|1-\lambda_{2}\right|<1$. Cryer and Chan, Time series, p. 399.

30 In the Chan test, the null hypothesis is an AR model versus the alternative hypothesis of a two-regime TAR model with constant noise variance. See Chan, 'Percentage points'.
} 
are now much smaller and insignificant, suggesting that there is little remaining nonlinearity. Moreover, each residual series is uncorrelated over time. We view these results as offering some support for the general TAR model.

\section{Insert Table 3}

Of the 423 monthly observations, the upper regime accounts for 22 observations. Silver shipments from Shanghai to Tianjin were, therefore, profitable in these months. The lower regime accounts for 42 observations where silver shipments in the opposite direction were profitable. The remaining 359 observations, representing 85 percent of the entire sample, underlie the middle regime. Thus, exploitable arbitrage opportunities did occasionally emerge in the study period, but they did not persist.

We now further test the possibility that the change in silver points occurred gradually over time, rather than instantaneously from the old to the new regimes, by using a moving window method to estimate the changes of thresholds. Taking a moving window of 120 observations (10 years), we estimate the silver point in each window. The window is shifted by 12 observations each time to limit the computational burden, that is, we re-estimate the restricted model and the general model using the sub-periods of January 1898-December 1907, January 1899-December 1908, etc. Figure 3 reveals that the silver points drop steadily in the 1910s, rather than decline gradually over the entire period. Thus, the turning point is much likely to be somewhere in the mid-1910s, which is roughly consistent with the result of endogenous breakpoint tests on the yangli spread series. Clearly, a rapid improvement in market integration occurred in the 1910s. 
Insert Figure 3

II.2. Daily data for nineteen cities in the 1920 s and 1930 s

We now turn to a new yangli data set with daily frequency, which allows us to capture the high-frequency dynamics likely obscured by the monthly data. Our daily data extends our geographic coverage to a total of nineteen cities including Shanghai and Tianjin but only for the period of the 1920s and early 1930s. We first examine the relationship of daily yangli data for Shanghai, Tianjin and Hankou for the 1920s. Hankou ranked after Shanghai and Tianjin as the most important financial center in the heartland of China. We have to discard the Hankou data after 1927 due to the serious war disruption by the Nationalists led Northern Expedition and the subsequent decree of banning silver outflow there. ${ }^{31}$ We have at our disposal a total of 2593 and 1356 daily yangli observations for the estimation of Shanghai-Tianjin and ShanghaiHankou markets, respectively for the periods of January 1921-December 1929 and January 1923-December $1926^{32}$

We estimate the general TAR model for the two pairs of cities and report the results in

Table $4 .{ }^{33}$ For the Shanghai-Tianjin markets the estimate of the silver point is 0.97 percent,

31 The radical left wing of the Kuomintang and the Communists occupied Hankou by force and issued the decree of a total embargo on silver on 17 Apr 1927. The decree imposed the circulation of only paper notes issued by government banks and prohibited the circulation and outflow of silver from Hankou (North-China Daily News, 19 Apr 1927, p. 11). The decree effectively took Hankou off the silver standard. With the founding of the Nationalist regime in Nanjing, Hankou restored the silver standard and reestablished the Hankou tael in Mar 1928. See Dai, 'History of silver', p.194.

32 Data for Tianjin yangli is drawn from the Bankers' Weekly and the Economic Statistics, and data for Hankou yangli is drawn from the Bankers' Magazine and the Economic Statistics. Data for Shanghai yangli and the exchange rates between the Shanghai tael and the Tianjin (or Hankou) tael are drawn from the Shenbao newspaper.

33 We also estimate the restricted model as in eq. 1 using daily data. There is no material change in the results on silver points. 
substantially larger than the corresponding result ( 0.74 percent) generated from the monthly data for the second sub-period using the TAR model. This higher threshold value in the daily data reveals that the monthly data to some extent obscured or 'smoothed' the high-frequency volatility. The middle regime is estimated to encompass almost 85 percent of the observations, implying that the yangli in two cities seldom strayed from each other even in the context of daily frequency data. The upper and lower regimes encompass 10 percent and 5 percent of the observations, respectively. Thus, we find some asymmetry in both the speed of adjustment and the number of observations underling the two outer regimes. The results from daily data confirm the validity of the unit root behavior in the middle regime and the outer-regime convergence toward the thresholds. That is, the middle regime shows very slow convergence, with a speed at a mere 2.9 percent within one day, or equivalently, a half-life of 24 days. In contrast, in the upper and lower regimes, deviations greater (in absolute value) than the estimated silver point will be, reduced by 11.3 percent and 3.9 percent respectively within one day.

\section{Insert Table 4}

The estimate of the silver points for the Shanghai-Hankou markets is 0.65 percent, smaller than the estimates of silver points for Shanghai-Tianjin markets. This is consistent with the fact that Hankou is well-connected with Shanghai by the Yangtze River with a distance of only 1000 against the 1300 kilometers distance between Tianjin and Shanghai. The estimates of convergence speed also matches well with the findings of the silver point arbitrage model, That is, the outer regimes shows fast convergence and the middle regime has a root much closer to unity. It was a more frequent occurrence that dollar was overvalued in the Hankou market 
relative to the Shanghai market, a result consistent with Hankou's net inflow of silver dollar.

We now turn to the second set of daily data for a total of nineteen cities for the brief period of 1921-23 and 1930-31. Figure 4 presents a map of all the cities in our sample. ${ }^{34}$ The yangli data for the period of 1921-22 are taken from the Monthly Report of Native Bankers' Association (1920-22), and for the period of 1930-31 taken from the Ten-day Bulletin of the Central Bank (1930-31). ${ }^{35}$ We use an analogous TAR model as in equation 2 to estimate the silver points between Shanghai and each of these cities. ${ }^{36}$ Figure 5 makes a simple linear plot between the estimated silver points of these cities (paired with Shanghai) and the least-cost path distance from Shanghai. ${ }^{37}$ To more fully capture the determinants of the magnitude of the silver points, we run the following regression:

$$
\theta_{i}=c_{0}+c_{1} D i s_{i}+c_{2} d_{\text {rail }, i}+c_{3} d_{B E, i}+c_{4} d_{L Y, i}+c_{5} d_{B E, i} \cdot d_{L Y, i}+\varepsilon_{i}
$$

where the dependent variable $\theta_{i}$ is the estimated silver point between city $i$ and Shanghai; $D i s_{i}$ is the corresponding least-cost path distance; $d_{B E, i}$ is an indicator variable representing that the sample period for city $i$ was in the Warlord Era, that is, it takes the value of 1 in the

34 Other than Shanghai, Tianjin and Hankou, there are six cities in Zhejiang province which are (sample period reported in parentheses): Hangzhou (Jan. 1921-Jan. 1923; July 1930-Dec. 1931), Huzhou (Jan. 1921-Dec. 1922), Jiashan (Jan. 1921-Dec. 1922), Jiaxing (Jan. 1921-Dec. 1922), Ningbo (Jan. 1921Dec. 1922), Xiashi (Jan. 1921-Dec. 1922); four cities in Jiangsu province: Suzhou (Jan. 1921-Jan. 1923), Xuzhou (Nov. 1930-Oct. 1931), Yangzhou (July 1930-Dec. 1931), Zhenjiang (Jan. 1921-Nov. 1921; July 1931-Dec. 1931); one in Anhui province: Wuhu (Oct. 1930-Dec. 1931); two in Jiangxi province: Jiujiang (July 1930-Dec. 1931), Nanchang (July 1930-Dec. 1931); two in Shandong province: Jinan (Sep. 1930-Dec. 1931) and Qingdao (July 1930-Dec. 1931); and one in Zhili province: Beijing (Jan. 1921-Dec. 1924).

35 Note that market exchange rates between taels in different cities only existed in major cities such as Shanghai, Tianjin and Hankou. Elsewhere parity ratios (the ratios of silver content) between taels were used in calculating yangli spread. The parity ratios are taken from Jin, Guonei Shangye, p. 233.

36 We do not measure integration between the network of all these cities partly due to the limitation of the data. Nevertheless, we believe that it does not affect our basic conclusions as the Chinese financial network was hierarchical, with Shanghai being at the center. Thus, active exchange market developed between Shanghai and remaining cities, but not between any pairs of them. As an official report observed that, 'Shanghai has long been China's financial clearing house ... Each area constantly ships its spare funds to Shanghai in order for them to be transferred to cash-short areas.' Shiyebu, Zhongguo Shiye Zhi, p. 243.

37 The least-cost paths for silver transportation are derived by taking the minimal transport costs from among rail, water and sea shipping in the 1920s, which are taken from Jin, Guonei Shangye, pp. 18-21. 
Warlord Era and 0 in the Nanjing Decade. $d_{\text {rail, } i}$ is an indictor variable representing that city $i$ is connected to Shanghai by railway. $d_{L Y, i}$ is an indicator variable representing that city $i$ is situated at the Lower Yangtze areas. The interaction term captures the difference in the slope coefficient of $d_{L Y, i}$ between the Warlord Era and Nanjing Decade. The reason for controlling for regional difference between the two periods is that researchers generally believe that commerce and transportation in the Lower Yangtze were more developed, and the Nanjing government's rule was centered in the Lower Yangtze. $\varepsilon_{i}$ is a random error.

\section{Insert Figure 5}

The results of equation 3 are presented in Table 5. We arrive at a significant and positive coefficient of Dis, which means every increase of distance of 100 kilometers from Shanghai increases the silver points by about 0.07 percentage point. The significant negative coefficient of $d_{\text {rail }}$ reveals silver point would decrease by additional 0.15 percentage point for cities connected by railway. The lack of significance of the coefficient estimates of $d_{B E, i}$ and the interaction term indicates that there was no substantial difference in the level of integration between two regions and two periods. ${ }^{38}$ If anything, these improvements had occurred in the 1910s. We show this more dramatically by inserting in Figure 5 the 1898-1911 ShanghaiTianjin silver point estimate (from Table 3), which stood at 2.21 percent compared with the 0.97

\footnotetext{
38 In some cases, silver points such as between Shanghai-Zhenjiang and Shanghai-Hangzhou shown in Fig. 5 even increased in the Nanjing era relative to the Beiyang decade. In fact, our regression for all the pairs of cities here shows that, controlling for other factors, silver points in the Nanjing era are slightly higher than the Beiyang decade but not statistically significant (Tab. 5). While difficult to interpret a statistically insignificant result, one possible explanation is that both international and domestic environment during the 1930s were more volatile than the 1920s.
} 
percent figure for the 1920s (see Table 4). If we use linear distances in equation rather than least-cost paths from Shanghai, results shown in Table 5 remained basically unchanged.

\section{Insert Table 5}

\section{III}

So far, all our tests on money market integration are inferred through the indirect observation based on the dynamics of yangli. We now try to test inferred silver points against actual quantities of silver flows and measured costs of the silver movement derived from contemporary accounts. We have compiled a dataset on actual silver flows, which allow us specifically test whether our estimated silver points help predict corresponding transaction volumes. Our dataset are weekly records on the actual volume of silver dollar shipments from Shanghai to Tianjin/Hankou, and silver dollar arrivals to Shanghai from Tianjin/Hankou, for the period of 1922-30, taken from the North-China Daily News in its Weekly Exchange Notes column (reported on every Friday). The weekly frequency nature of our silver flow data does not perfectly match the nine (six) days shipping time between Shanghai and Tianjin (Hankou)

markets. In Figures 6 and 7, we made adjustment by using the maximum of the yangli spread in the three days before the actual shipment from Shanghai, or the minimum of the yangli spread in the ten (seven) days before the actual arrival to Shanghai from Tianjin (Hankou). In these figures we also plot our silver point estimated from the TAR models using daily data. On the bottom of these figures we show the actual volume of silver dollar movement.

\section{Insert Figures 6 and 7}

A visual inspection of the figures reveals a general correspondence between the magnitude 
of the yangli spread exceeding the silver points and the actual flows of the silver dollars. Almost all of the large exports from Shanghai occurred when yangli spread were above the estimated thresholds and only limited flows occurred when the spread fell within the bounds of the silver points. Figures 6 and 7 also reveal other factors accounting for the silver moments. Agricultural seasonality for Shanghai and Tianjin (usually late autumn and early winter) is one relatively independent factor. Another factor is major disruptions such as the Jiangsu-Zhejiang War (September and October of 1924) and the Northern Expedition (1927-8) caused major disruptions in silver exchanges.

We now formally test our insights by estimating a Probit model. In this model, the dependent variable is a dummy which equals to one when there is an occurrence of silver flows between the pair of cities. The key explanatory variable $\left(d_{y s, t}\right)$ is a dummy variable which equals to one when the instance of the yangli spread exceeds our preferred silver point estimate (that is, $>0.97$ percent or $<-0.97$ percent for the Shanghai-Tianjin markets, and $>0.65$ percent or $<-0.65$ percent for the Shanghai-Hankou markets). Additional controls include dummy variables for the period for the Jiangsu-Zhejiang War, and the Northern Expedition for the Shanghai/Hankou trade, and for the months of October and November, to represent the peak agricultural harvest season in Northern China. ${ }^{39}$ As shown in Table 6, we arrive at positive and highly significant coefficients on $d_{y s, t}$ while coefficients of other control variables have the expected signs. For example, in the case of silver flow from Shanghai to Tianjin, the coefficient of $d_{y s}$ is estimated to be 0.67 , implying the probability of the occurrence of silver flows when

39 The Northern Expedition lasted longer, but our dummy only controls the period from Jan. to Dec. 1927 when Shanghai was affected. 
$d_{y s}=1$ (the yangli spread exceeds the silver point) is about 4 times that when $d_{y s}=0$ (the spread fell within the bounds of the silver points). Thus, the economic and statistical significance of this measure is substantial, leading to a measure of corroboration between the estimates of our model and independent volume flow data. ${ }^{40}$

\section{Insert Table 6}

We now compare our silver point estimates to contemporary accounts of silver dollar movement costs, which are available for the mid-1920s. In the Tianjin-Shanghai silver trade, there were two principal routes: from Shanghai by steamer to Tianjin which entailed a cost of 0.76 percent (including freight and insurance premium); or from Shanghai by the TianjinNanjing Railroad and the Shanghai-Nanjing Railroad which entailed a cost of 0.74 percent. ${ }^{41}$ Adding a nine-day interest with an annualized 5 percent rate would raise the total cost to 0.88 percent by steamer or 0.86 percent by railroad, respectively. These contemporary accounts on silver shipping costs are close to or slightly lower than our silver point estimates of 0.97 percent for the Shanghai-Tianjin markets in the 1920s, which is quite reasonable as silver points estimates may well include a risk premium for the volatility of yangli.

Analogously, the silver point estimate for the Shanghai-Hankou markets also matches well with actual costs of the silver trade. The cost of shipping silver dollar from Shanghai to Hankou by steamer via the Yangtze River was 0.51 percent, adding a 6-day interest would increas the total cost to 0.60 percent. $^{42}$ Also, our silver point estimate is only slightly higher than actual

\footnotetext{
40 We also conduct a Tobit test with the dependent variable as the actual quantities of silver flows. The results are similar to our Probit estimation here.

41 Jin, Guonei Shangye, pp. 19-21.

42 Ibid., p. 18.
} 
costs. Given this close correspondence, there were apparently no significant informational barriers to the silver trade within China in this period.

We can also make a comparison of our Shanghai-Tianjin silver point estimates with those between Shanghai and New York City at that time. There are three routes for the New YorkShanghai silver trade: from New York by direct steamer (or through bill of lading by steamer via San Francisco) which entailed a cost of 1.71 percent; or from New York via Seattle, Vancouver, or Victoria by rail which entailed a cost of 2.05 percent; or from New York via London which entailed a cost of 2.65 percent. ${ }^{43}$ These costs are consistent with recent studies by Jacks et al. which show their silver point estimates across Shanghai and New York to be about 2.0 percent in the $1920 \mathrm{~s}$. Thus, both the silver point estimates and reported shipping costs of New York-Shanghai are consistently about two to three times those of the Shanghai-Tianjin figures.

Finally, we can make a comparison of our silver point estimates with the well-known estimates of the gold points under classical gold standard between London and New York City. Officer, for instance, estimates gold points of $0.61-0.69$ percent for the period of 1890-1906, while Canjels et al. estimate gold points of 0.67 percent for the period of $1879-1913 .^{44}$ Although not so different in magnitude, these pairs of estimates are not exactly comparable as they are for different periods, for different distance-Tianjin and Shanghai being far closer than that between London and New York - and different value to weight ratio with silver being much lower than gold. With these caveats, our available silver points estimates and shipping costs

${ }^{43}$ Kann, The currencies of China, p. 10.

${ }^{44}$ Officer, 'The remarkable efficiency'; Canjels, et al., 'Measuring market integration'. 
data coming from the three different comparison lead us to conclude that by the 1920s, Chinese

financial market integration was moving closer to the standard of the advanced countries.

\section{IV}

Our study has demonstrated significant improvements in China's silver market integration from the late $19^{\text {th }}$ century onward and reveals surprising new insights on China's Warlord Eraone of the most eventful decade in world and Chinese history — as the beginning of a major breakthrough in monetary and financial markets in the aftermath of WWI on the international front and the collapse of Qing Empire domestically. Although our findings are based on rigorous econometrics analysis of the most comprehensive of any existing studies so far, we should qualify our findings with two limitations to our current data sets. Firstly, we only have one yangli data series for the period before the 1920s, namely, the monthly data of Shanghai-Tianjin series in $1898-1933 .{ }^{45}$ Second, most of the nineteen cities in our 1920s and 1930s data series are located in Central and Northern China. These are largely due to the fact that formal yangli market did not properly establish in other areas or periods. In many cities in Northern and Southwestern parts of China, Eagle, Beiyang and various dragon dollars along with the national dollars co-existed throughout the 1920s. In Chongqing, Guangzhou or Northeastern parts of

\footnotetext{
45 Nevertheless, the financial integration between these two major cities was reflective of the urban economy in their respective macro-regions. Given the hierarchical financial network was with Tianjin serving as the center of Northern China and Shanghai as the center of both the Lower Yangtze and the whole of China, they acted to balance the peaks and troughs of cash expenditures in different cities. As Ma observes, during the peak season for trade of northern agricultural products, silver currency was shipped from Shanghai to Tianjin and thence distributed to other places through the Tianjin money market. When enormous amounts of currency were moved to northern markets, millions of silver dollars were shipped into Shanghai from areas with surplus currency in South China. That is, currency was not shipped directly to north from south cities, but with Shanghai and Tianjin as the centers intermediating between them. Ma, 'Traditional finance'.
} 
China which were partly under Japanese colonization, other forms of silver taels and dollars circulated. ${ }^{46}$ In spite of that, we have reasons to believe that monetary integration occurred at a national level perhaps with varying degrees of depth. Our discussion below on silver integration is focused on Northern and Central China.

One plausible driving force behind this enhanced integration was the rise of new transport and information infrastructure. Most notably, completed in 1912, the Tianjin-Nanjing Railway, joint with the Shanghai-Nanjing Railway and Shanghai-Hangzhou Railway constructed in 1908 and 1916 respectively, became a major artery linking China's North and South. Compared with road or water transport, railroads offered much faster, cheaper and safer delivery, an advantage far more significant for high value silver shipments than low value bulky commodities. For example, in the 1930s, trains only needed four hours (or six hours in 1908) to travel between Shanghai and Hangzhou compared with 24 hours needed by water. ${ }^{47}$ The overtime decline in rail freight made rail transport even cheaper than waterways by the 1920s and 1930s, especially along the Yangtze River. ${ }^{48}$ More importantly, with modern insurance rail transport were far more secure than traditional land routes. ${ }^{49}$ As seen in Table 5, railroad reduced silver points by over 0.15 percentage point, a substantial reduction given that average silver point is 0.59

\footnotetext{
46 In Chongqing, the main currency was a ten-tael unit sycee with the national and other silver dollars used as subsidiaries. See, for example, Anonymous, 'Chongqing zhi Tongyong Huobi' ['The currency in Chongqing', Yinhang Zhoubao [Banker's Weekly], 10 (23) (1918), p. 19. In Guangzhou, Haoyang, which consisted of five 20 -cent coins containing 18.81 grams of fine silver was the principal currency. Lewis and Wang, 'Wholesale prices'.

47 Yue, 'Jindai Changjiang'.

${ }^{48}$ For example, in the 1920s, silver shipments by rail for Shanghai-Nanjing and Shanghai-Zhenjiang routes cost $0.14 \%$ and $0.15 \%$ compared with $0.33 \%$ and $0.27 \%$ respectively for waterways. Jin, Guonei Shangye, pp. 19-20.

49 The robbery of silver shipments on the land route were frequently reported in the Shenbao newspapers. See, for example, the issues for 2 Nov. 1902, p. 12; 8 Sep. 1906, p. 17; 31 Mar 1907, p. 12.
} 
percentage point.

Likewise, the expansion of new information infrastructure such as postal services and telegraphs from the late $19^{\text {th }}$ century on also rapidly enhanced money market integration as vividly captured in the following newspaper report on 26 August 1932: 'Yesterday morning, a certain native bank in Tianjin received a telegram that there was a surge in the price of silver dollar in Shanghai, this was immediately followed by a spike in silver dollar in Tianjin. But soon in the afternoon, another telegram arrived to inform that it was false information. Very quickly silver dollar market in Tianjin returned to the original state' ${ }^{50}$

Another more consequential factor is the monetary and financial transformation marked by the rise of a modern banking system from the end of the $19^{\text {th }}$ century. By 1911 , China saw the establishment of important government banks such as Bank of China and Bank of Communication as well 17 private commercial banks, mostly clustered in Western treaty ports such as Shanghai which offered relative security and favorable property rights regimes particularly during the recurrent phases of national instability following the 1911 political regime change. Shanghai saw the rise of a strong and largely autonomous banking community led by the Chinese Bankers' Association (CBA) and the Native Bankers' Association (NBA) established in 1915 and 1917 respectively. They coordinated collective action, established trading standards, publicized important financial statistics.

Although it was the Beijing government that issued the national dollars, banking communities played a key role in defending its reputation and purity. ${ }^{51}$ It was CBA that

50 Morota, 'Money Supply'.

51 A prominent example was the debasement incident in 1925. When it was brought to light that 
coordinated with modern Chinese banks to close the exchange market for the dragon dollar and eagle dollar in 1915 and 1919 in Shanghai, respectively, and opted for a single national dollar exchange market. Overtime, the 'countable' dollar outperformed 'weighable' sycee as a medium of exchange, gaining an increasing share in China's monetary system. For instance, in the silver reserve of Shanghai banks, the ratio of silver dollars relative to silver ingots (sycee and bar silver) measured in value was 0.37 in 1918 , but rose dramatically to $0.63,0.88,1.00$ and 2.29 in 1921, 1925, 1928 and 1931, respectively. ${ }^{52}$ This eventually paved the way for the currency reform of 1933 under the Nanjing Government, which abolished sycee and tael and retained dollar as the sole monetary standard.

Another monetary transformation is the increasing popularity of banknotes and deposits associated partly with the rapid growth of new financial instruments such as public debt. ${ }^{53}$ The system of Chinese bank note issuance were largely run on a model of free banking with multiple public and private banks, Chinese or foreign, issuing silver-convertible banknotes based on reputation mechanism. Again, the Chinese banking communities initiated efforts to enhance the reputation of banknotes by publicizing statistics on bank reserves of note-issuing banks and establishing independent monitoring committees as well as other institutional innovations. ${ }^{54}$

thousands of debased dollars were circulating in Shanghai, the CBA and NBA telegraphed to the Ministry of Finance, the Jiangsu civil authorities and the Nanjing Mint (North-China Daily News, 28 Aug. 1925, p. 12). After an investigation order by the Jiangsu provincial governor, within one week the Shanghai constabulary discovered the mint and models of the debased dollars by a government functionary. According to the request of CBA and NBA, the debased dollars were finally redeemed by the Jiangsu provincial authorities and destroyed (China Press, 16 Sep. 1925, p. 1).

52 People's Bank of China, Shanghai Qianzhuang, p. 584.

53 The rise of Chinese governmental bonds was closely connected with China Maritime Customs administered mostly by British staff.The domestic banks were the largest bondholders, who held bonds both for investment and as a reserve to cover banknotes. China's banking regulations allowed banks to use governmental bonds - in the range of $40 \%$ - to serve as reserves for bank notes, with the rest in some form of species. Brandt and Sargent, 'Interpreting new evidence'.

54 Yang, Zhongguo Jinronglun, pp. 124-5. 
The substitution effect of banknote over silver specie became increasingly obvious as Feng observed that, 'In recent years, banknotes are widely used in Inland and agricultural producing areas...Even in times of political unrest and economic turmoil, banknotes remain unblemished in creditability and convertibility. ${ }^{55}$ Newly compiled macro-statistics reveal that while total money supply (M1) increased at an annual rate of 4.3 percent, the bank notes and deposit components of M1 surged at a remarkable annual rate of 9.5 percent during $1910-35 .{ }^{56}$ It seems that the turning point marked by a sharp uptick in overall trend of banknotes and deposits fell around the year of 1917-18 which broadly corresponds to the timing of the rise of Chinese modern banking, transportation and information infrastructure.

Understandably, Shanghai played a key role in China's monetary transformation with convertible banknotes issued by large banks, sometimes generally referred to as 'Shenchao' (Shanghai notes), circulating in major commercial centers with no discount by the $1920 \mathrm{~s} .{ }^{57}$ We can examine impact of bank notes on money supply by examining the seasonal patterns in banknotes issued and silver reserves of the banks in Shanghai. As we can see in Figure 8, the pattern of seasonals in banknote issue and silver reserves are reverse, indicating bank's adjustment in note issues and reserve ratios to mitigate cyclical demand for cash. In Figure 8, we also insert the seasonal patterns in Shanghai yangli, calculated by regressing the Shanghai yangli on 12 seasonal dummies, with the monthly coefficients normalized to sum to 1 over

55 Feng, 'Yangli yu Yinchai'.

56 Rawski, Economic growth, p. 157.

57 For the circulation of banknotes outside the borders of the issuing branch, in particular, the circulation of Shenchao in Hankou during the 1920s, see Kuroda, 'The collapse', p. 116. For circulation of Shenchao in Tianjin, see Morota, 'Money Supply'. 
twelve-month period. It shows that the quantitative patterns of bank note issues more or less track the peak and trough of yangli (high at the period of various agricultural trade and squaring accounts demand at the end of the Chinese lunar year, respectively, and low in the summer). ${ }^{58}$ Given that the 1910s marked the rise of modern banking, we are possibly observing that increasing note issue have provided a much more elastic currency to smooth the seasonality in money market and enhance market integration across Shanghai and Tianjin and beyond. ${ }^{59}$

\section{Insert Figure 8}

Based on the compilation of a high frequency monetary data and rigorous econometrics tests, our paper contributes new insights on Chinese monetary integration and economic performance in the late-Qing and Republican era and the workings of silver regimes in historical eras. Throughout the whole tumultuous period in our sample, the period of 1898-1911 was relatively stable under a single government until the collapse of Qing in 1911 which heralded a period of economic and political disruption. But it was precisely from the 1910s Chinese monetary and financial transformation took off, marched on during the 1920s and 1930s in spite of the disruptions by warfare and revolution. ${ }^{60}$ While political changes alone were not solely

58 The amplitude of the seasonal pattern in Shanghai yangli is approximately $0.8 \%$ of parity value. That is, yangli is approximately $0.4 \%$ higher than average in the fall and Feb. and $0.4 \%$ lower than average in the summer. The seasonal patterns of the yangli in Hankou roughly corresponds with the Shanghai series. 59 There has been a large literature on the change in the seasonality of monetary market in the gold countries. In particular, following the creation of the Federal Reserve System in 1914, seasonals in nominal rates almost completely disappeared, due partly to Fed's anti-seasonal monetary policy to smooth interest rates at that time. See, for example, Miron, 'Financial panics'; Meltzer, A history.

60 Like more other market integration studies, our data are limited to major urban centers along the coast or main transport routes only. 
responsible for the financial transformation during China's Republican era, it seems a combination of domestic improvements coalesced to bring about the efficiency progress of China's silver regime. In particular, China's move from sycee, imported silver dollars toward a single national silver dollars and eventually towards credible banknotes convertible to silver became the hallmark of China's transformation in her own monetary standard. The prolific discussion in the literature on the choice of gold versus silver standards for China neglected this most critical elements of the internal monetary issues in China. ${ }^{61}$

More importantly, the monetary and financial transformation occurred in a context of institutional revolution championed by China's civil and commercial group from below during China's relatively rare Beiyang period of political decentralization. It was ironic that monetary fragmentation that had actually prevailed under traditional China's highly centralized political regime was gradually overcome in an era of political decentralization and disintegration during the early $20^{\text {th }}$ century. Hence, our study also hints at the central role of political institutions as a possible key to understanding the Great Divergence between Western Europe and China in the early modern era.

\section{References}

Bai, J. and Perron, P., 'Estimating and testing linear models with multiple structural changes.' Econometrica, 66 (1998), pp. 47-78.

\footnotetext{
${ }^{61}$ For example, Brandt and Sargent, 'Interpreting new evidence'; Friedman, 'Franklin D. Roosevelt';
} Rawski, 'Milton Friedman'; Shiroyama, China during the Great Depression. 
Bordo, M. and Rockoff, H., 'The gold standard as a good housekeeping seal of approval', Journal of Economic History, 56 (1996), pp. 389-428.

Brandt, L. and Sargent, T., 'Interpreting new evidence about China and US silver purchases', Journal of Monetary Economics, 23 (1989), pp. 31-51.

Brandt, L., Ma, D., and Rawski, T., 'From divergence to convergence: reevaluating the history behind China's economic boom', Journal of Economic Literature, 52 (2014), pp. 45-123.

Canjels, E., Prakash-Canjels, G., and Taylor, A., 'Measuring market integration: foreign exchange arbitrage and the gold standard, 1879-1913', Review of Economics and Statistics, 86 (2004), pp. 868-82.

Chan, K., 'Percentage points of likelihood ratio tests for threshold autoregression', Journal of the Royal Statistical Society, Series B, 53 (1991), pp. 691-6.

Cryer, J. and Chan, K., Time series analysis with applications in $R$ (Springer, 2008).

Dai, J., Zhongguo Jindai Yinliangshi [A History of silver taels in modern China] (Beijing, 2007).

Feng, Y., 'Yangli yu Yinchai Zhiyiyi' ['The meaning of silver dollar exchange rate and lending rate'], Yinhang Zhoubao [Banker's Weekly], 10 (29) (1926), pp. 41-5.

Fernholz, R., Mitchener, K., and Weidenmier, M., 'Pulling up the tarnished anchor: the end of silver as a global unit of account', Journal of International Money and Finance, 74 (2017), pp. 209-28.

Fetter, W. and Bratter, H., 'China and the flow of silver', Geographical Review, 26 (1936), pp. $32-47$.

Friedman, M., 'Franklin D. Roosevelt, silver, and China', Journal of Political Economy, 100 (1992), pp. 62-83.

Hansen, B., 'Inference in TAR models', Studies in Nonlinear Dynamics and Economics, 2 (1997), pp. 1-14.

Jacks, D., Yan S., and Zhao L., 'Silver points, silver flows, and the measure of Chinese financial integration', Journal of International Economics, 108 (2017), pp. 377-86. 
Jin, B., Guonei Shangye Huidui Yaolan [A guidebook of domestic commercial exchange] (Shanghai, 1925).

Kann, E., The currencies of China (Shanghai, 1927).

Kong, M., eds., Nankai Jingji Zhishu Ziliao Huibian [Nankai economic indicators] (Beijing, 1988).

Kuroda, A., 'The collapse of the Chinese imperial monetary system', In K. Sugihara, eds., Japan, China, and the growth of the Asian international economy, 1850-1949 (Oxford, 2005), pp. 103-27.

Lewis, A. and Wang L., 'Wholesale prices in different cities in China and Hongkong, 1930 to 1936'. Economic Facts, 2 (1936), pp. 17-31.

Ma, D., 'Economic growth in the Lower Yangzi region of China in 1911-1937: a quantitative and historical analysis', Journal of Economic History, 68 (2006), 355-92.

Ma, J., 'Traditional finance and China's agricultural trade, 1920-1933', Modern China, 34 (2008), pp. 344-71.

Meissner, C., 'A new world order: explaining the international diffusion of the gold standard, 1870-1913', Journal of International Economics, 66 (2005), pp. 385-406.

Meltzer, A., A history of the Federal Reserve (Chicago, 2003).

Miron, J., 'Financial panics, the seasonality of the nominal interest rate, and the founding of the Fed', American Economic Review, 76 (1986), pp. 125-40.

Mitchener, K., Shizume, M., and Weidenmier, Ma., 'Why did countries adopt the gold standard? Lessons from Japan', Journal of Economic History, 70 (2010), pp. 27-56.

Morota, H., 'Money supply mechanism and financial modernization in 1920-30 Tianjin’, Social Economic History Review, 79 (2013), pp. 69-90.

Officer, L., 'The remarkable efficiency of the dollar-sterling gold standard, 1890-1906', Journal of Economic History, 49 (1989), pp. 1-41.

People's Bank of China (Shanghai Branch), Shanghai Qianzhuang Shiliao [The archival 
materials of Shanghai traditional banks] (Shanghai, 1960).

Rawski, T., 'Milton Friedman, silver, and China', Journal of Political Economy, 101 (1993), pp. $755-8$.

Rawski, T., Economic growth in prewar China (Berkeley, 1989).

Shangwu Yinshuguan, eds., Zhongguo Xinyutu [New atlas of China] (Shanghai, 1925).

Shiyebu Guoji Maoyiju, Zhongguo Shiye Zhi: Jiangsusheng [Records on China's industries: Jiangsu], vol. 2 (Shanghai, 1932).

Shiroyama, T., China during the Great Depression: market, state, and the world economy, 1929-1937 (Cambridge, 2008).

Shiue, C., 'Transport costs and the geography of arbitrage in eighteenth-century China', American Economic Review, 92 (2002), pp. 1406-19.

Stanfield, B. and Keller, W., 'Markets in China and Europe on the eve of the industrial revolution', American Economic Review, 97 (2007), pp. 1189-216.

Wu, D. and Hu Y., 'Shanghai Jinrongzhi Jijie’ ['Seasonal in Shanghai finance'], Zhengzhi Jingjixue Pinglun [Review of Political Economics], 2 (1937), pp. 471-84.

Wu, D., 'Yige Xinde Waihui Zhishu' ['A new exchange rate index'], Zhengzhi Jingjixue Pinglun [Review of Political Economics], 3 (1935), pp. 463-509.

Yang, Y., Zhongguo Jinronglun [Chinese finance] (Shanghai, 1936).

Young, John. 'The Shangai Tael', American Economic Review, 21 (1931), pp. 682-4.

Yu, S., 'Zhengjin Zhoubao lun Shanghai Yinyuan Liutong Xianzhuang' ['The current situation of silver dollar circulation in Shanghai'], Yinhang Zhoubao [Banker's Weekly], 12(10) (1928), pp. 26-9.

Yue, Qintao. 'Jindai Changjiang Sanjiaozhou Diqude Jiaotong Fazhan yu Renkou Liudong' ['Traffic development and population flow in modern Yangtze River delta'], Zhongguo Jingjishi Yanjiu [Researches in Chinese Economic History], 4 (2014), pp.155-67.

Zhang, J., Zhonghua Bizhishi [A history on Chinese currency system], vol. 1 (Beijing, 2013). 